\title{
Pengaruh Webrooming terhadap Confident, Smart Shopping Feeling, User-generated Content, dan Search Process Satisfaction
}

\author{
Sri Hartini \\ S. Nurul Hidayati \\ Manajemen, Universitas Airlangga, Indonesia \\ Korespondensi penulis: snurulhidayati92@gmail.com
}

\begin{abstract}
Recently, many people are switching from conventional shopping to digital shopping. even so, people feel that online shopping is less secure. Finally, many consumers search for information through the internet before shopping at brick-and-mortar stores. This study investigates how webrooming affects consumers' experience and determines the effect of webrooming on consumer confidence, smart shopping feeling, user-generated content, and search process satisfaction in the beauty industry. The population in this study were all the beauty industry consumers who experience webrooming in the shopping process. The total sample used in this study was 166 people using purposive sampling. The result obtained from this study finds that webrooming has a significant and positive effect on confidence, smart shopping feeling, user-generated content. Both factors, confidence and smart shopping feeling subsequently significant and have a positive effect on search process satisfaction.
\end{abstract}

Keywords: Webrooming; Confident; Smart shopping feeling; User-generated content; Search process satisfaction.

\begin{abstract}
Abstrak. Saat ini, orang-orang banyak beralih dari sistem belanja konvensional ke digital. Namun, beberapa orang merasa melakukan belanja online kurang aman. Akhirnya, banyak konsumen yang melakukan pencarian informasi melalui internet sebelum berbelanja di toko offline. Penelitian ini bertujuan untuk mengetahui pengaruh webrooming terhadap confident, smart shopping feeling, dan user-generated content yang mempengaruhi search process satisfaction pada produk kecantikan. Penelitian ini menggunakan metode kuantitatif dengan jumlah sampel sebanyak 166 orang yang ditentukan berdasarkan metode purposive sampling. Hasil penelitian ini menemukan bahwa webrooming berpengaruh positif terhadap confident, smart shopping feeling, user-generated content, dan search process satisfaction, sedangkan confident dan smart shopping feeling berpengaruh positif terhadap search process satisfaction.
\end{abstract}


Kata kunci: Webrooming; Confident; Smart shopping feeling; User-generated content; Search process satisfaction.

Article Info:

Received: August 23, $2021 \quad$ Accepted: October 10, $2021 \quad$ Available online: October 26, 2021

DOI: http://dx.doi.org/10.30588/jmp.v11i1.881

\section{LATAR BELAKANG}

Secara langsung dan tidak langsung, penggunaan internet berdampak terhadap perubahan perilaku pencarian informasi pada zaman sekarang, khususnya kaum remaja lebih suka melakukan pencarian informasi melalui internet karena lebih mudah, efisien, dan informasinya lebih update (Nurhayati, 2014). Perkembangan perilaku konsumen di Indonesia dalam pencarian informasi ketika akan berbelanja, mereka mulai beralih dari cara konvensional menjadi pencarian secara online atau digital (Maharsi, 2012). Internet memberikan konsumen kemampuan akses yang belum pernah terjadi sebelumnya dalam pencarian informasi. Riset yang dilakukan oleh PEW internet and American life project menunjukkan bahwa tujuh dari 20 aktifitas melalui internet mengacu pada aktifitas pencarian informasi (Mothersbaugh \& Hawkins, 2015). Hal itu menunjukkan bahwa internet secara umum telah menjadi alat pencarian informasi dan proses pengambilan keputusan. Para pengguna internet berharap untuk menemukan informasi produk pada website resmi untuk melakukan pembelian secara offline. Bagi konsumen yang ingin mencari alternatif terbaik terhadap barang yang ingin dibelinya, internet merupakan salah satu alat yang paling tepat untuk saat ini.

Meskipun orang-orang banyak beralih dari pola belanja konvensional ke digital, tetapi masih ada beberapa orang yang merasa bahwa belanja online kurang aman (Flavián, Gurrea, \& Orús, 2019). Penelitian yang dilakukan oleh Nielsen.com (2019) menemukan bahwa $63 \%$ responden dalam enam bulan terakhir sebelum melakukan pembelian, mereka melakukan riset melalui internet untuk memperoleh informasi produk yang lebih detail, $52 \%$ responden melakukan perbandingan harga di internet, dan $46 \%$ mencari penawaran khusus atau kupon, dan 57\% responden merasa memiliki keraguan bahwa berbelanja digital akan dapat menyimpan informasi pribadi mereka secara aman. Webrooming adalah istilah yang digunakan untuk menyebut kebiasaan perilaku hibrida pelanggan dalam kegiatan berbelanjanya. Webrooming dapat diartikan bahwa ketika pelanggan melakukan pencarian informasi dan data barang secara online, atau hanya sekedar membandingkan harga (Flavián et al., 2019; Kang, 2018). Menurut penelitian sebelumnya oleh Smith (2015), lebih dari $40 \%$ pelanggan yang berbelanja di toko juga secara bersamaan sedang melakukan pencarian informasi melalui handphone terkait produk yang ingin dibelinya. Zaman sekarang, orang-orang biasa menggunakan smartphone mereka untuk melakukan pencarian informasi terkait produk, sementara mereka juga melakukan kunjungan di toko secara offline (van Bruggen, Antia, Jap, Reinartz, \& Pallas, 2010).

Salah satu alasan mengapa konsumen lebih menyukai webrooming adalah upaya untuk mengurangi rasa ketidakpastian mengenai produk yang akan dibeli. Penelitian sebe- 
lumnya mengakui bahwa internet lebih banyak digunakan sebagai media pencarian informasi, sedangkan toko offline adalah media utama untuk melakukan transaksi pembelian (Flavián et al., 2020; Yadav \& Pavlou, 2014). Pada tahun 2018, sekitar 44\% pembeli mengatakan bahwa ia membeli berdasarkan pengaruh dari konten di website. Hal itu menunjukkan bahwa perilaku webrooming lebih banyak dilakukan daripada showrooming atau pembelian online. Skenario webrooming dapat digambarkan sebagai berikut, ketika customer sedang melakukan surfing di media sosial, ia tertarik dengan sebuah produk lipstik yang digunakan oleh seorang model. Produk tersebut memiliki warna yang sangat bagus di bibir model. Merasa tertarik terhadap produk tersebut, maka customer ingin mencoba produk secara langsung dengan mendatangi toko ritel offline untuk memastikan kecocokan warna lipstik dengan bibirnya dan memutuskan untuk membelinya. Pada skenario lainnya, ketika customer melihat produk sepatu yang digunakan oleh seorang selebgram, ia tertarik dan melakukan pencarian infromasi mengenai sepatu tersebut, seperti mereknya, bahannya, dan lokasi pembeliannya. Karena ingin memastikan ukuran dan kenyamanan secara langsung, maka customer memutuskan untuk mendatangi toko offline dan melakukan pembelian.

Webrooming merupakan salah satu perilaku yang efektif untuk meningkatkan kepuasan dan loyalitas pelanggan, serta menjadi penentu kelangsungan perusahaan (Arora \& Sahney, 2019). Pada kenyataaannya, pelanggan lebih sering melakukan webrooming daripada kegiatan cross-channel lainnya, sehingga mereka merasa lebih puas. Hal itu disebabkan karena persepsi pelanggan yang merasa percaya diri (confident) bahwa mereka melakukan keputusan yang tepat. Perasaan confident yang dirasakan oleh konsumen akan menimbulkan perasaan puas dalam proses pencarian informasi (search process satisfaction), karena konsumen memiliki keyakinan terhadap proses yang dilakukan dalam pencarian informasi mengenai produk yang akan dibeli (Flavián et al., 2019). Webrooming memiliki pengaruh positif terhadap search process satisfaction, yaitu konsumen melakukan webrooming dengan mengambil manfaat adanya internet untuk mencari sebanyak-banyaknya informasi sebelum melakukan pembelian agar dapat meminimalkan risiko yang akan dihadapi (Flavián et al., 2020). Hal tersebut dapat meningkatkan perasaan percaya diri dan smart shopping feeling dalam proses pencarian informasi. Search process satisfaction adalah kepuasan terhadap pencarian informasi yang aktual (Flavián et al., 2020; Kozup, Creyer, \& Burton, 2003).

Meningkatnya pengguna internet terutama media sosial menyebabkan peningkatan user-generated content, dan biasa digunakan sebagai alat marketing yang sangat powerful (Kang, 2018). User-generated content adalah konten media yang dihasilkan oleh pengguna publik atau masyarakat dalam bentuk media online (seperti foto, review, video, podcast, konten forum, komen, dan konten blog) yang dihasilkan, diedarkan, dan dikonsumsi oleh pengguna publik (Kang, 2018). Media sosial dijadikan sebagai salah satu komponen marketing mix pada zaman sekarang. Media sosial memberikan wadah bagi konsumen untuk melakukan word of mouth yang nantinya menghasilkan user-generated content (Kang, 2018). Perusahaan yang mengimplementasikan marketing di media sosial dan internet menunjukkan peningkatan pada exposure kepada konsumen. Perusahaan yang mencoba menggunakan media sosial dan internet sebagai salah satu strategi marketing mendapatkan peningkatan penjualan dalam tiga tahun terakhir (Daugherty, Eastin, \& Bright, 2008). 
Industri kecantikan adalah salah satu industri yang paling cepat perkembangannya di Asia Pasifik salah satunya Indonesia (Mangkuto, 2019). Mengikuti perkembangan industri 4.0, dunia kecantikan juga memiliki istilah beauty 4.0, yaitu kecantikan bukan lagi hal personal atau "personal beauty." Namun, Hal itu sudah bergeser menjadi social beauty. Banyak akun media sosial, baik pribadi maupun yang sengaja dibuat, untuk dijadikan platform berbagi informasi mengenai dunia kecantikan. Google barometer 2019 mengungkapkan bahwa pencarian mengenai kecantikan naik sebanyak 30\% sejak tahun 2019 (Annur, 2019). Pencarian informasi mengenai kecantikan di internet meningkat dari tahun ke tahun. Peningkatan tersebut bukan saja meningkatkan jumlah penjualan industri kecantikan, bahkan tren ini dapat membentuk pasar baru berupa industri entertaiment pada bidang review produk kecantikan di kalangan remaja digital. Banyaknya permintaan dan peminat konten kecantikan menunjukkan banyaknya pencarian informasi terkait beauty product via internet. Pesatnya industri kecantikan dalam dunia digital di Indonesia perlu diteliti lebih jauh dan dipelajari lebih lanjut oleh pemasar. Ini menjadi alasan menjadikan beauty product sebagai obyek penelitian ini.

Selain itu, hasil penelitian-penelitian sebelumnya menyebutkan bahwa webrooming dapat mempengaruhi confident (Flavián et al., 2019), smart shopping feeling (Flavián et al., 2019, 2020), search process satifaction (Flavián et al., 2019), dan user-generated content (Kang, 2018). Selanjutnya, smart shopping feeling dan confident mempengaruhi search process satisfaction (Kang, 2018), sedangkan user-generated content mempengaruhi search process satisfaction (Colicev, Kumar, \& O’Connor, 2019). Dari uraian tersebut, penelitian ini bertujuan untuk membuktikan apakah webrooming mempengaruhi confident, smart shopping feeling dan user-generated content, yang pada gilirannya juga berdampak pada search process satisfaction.

\section{KAJIAN TEORITIS}

\section{Webrooming}

Webrooming merupakan perilaku konsumen yang memeriksa suatu produk secara online, sebelum mereka membuat keputusan akhir untuk membeli produk tersebut secara offline (Arora \& Sahney, 2019). Pemeriksaan produk secara online (via internet) dimaksudkan untuk mengumpulkan informasi sabanyak mungkin mengenai produk yang akan dibeli. Ada beberapa alasan mengapa konsumen memilih untuk melakukan webrooming atau berbelanja di toko secara offline. Salah satunya adalah ketidaksabaran konsumen menunggu jeda waktu pengiriman barang dan konsumen tidak ingin mendapatkan barang yang tidak sesuai dengan keinginan ketika berbelanja online (Flavián et al., 2019). Alasan lain mengapa konsumen memilih melakukan webrooming adalah ketika mereka ingin terlibat secara fisik dengan produk, meskipun sebelumnya mereka telah mencari informasi tentang kualitas produk melalui website.

Hasil penelitian oleh Devinder (2014) menyatakan bahwa pencarian informasi di internet adalah salah satu pelengkap dalam proses pengambilan keputusan dan bukan pengganti kegiatan mengunjungi toko offline, sedangkan dalam perspektif ekonomi, webrooming merupakan salah satu upaya untuk meningkatkan manfaat, seperti membuat kepu- 
tusan yang benar, menemukan harga yang lebih baik, dan keuntungan psikologikal lainnya, serta upaya meminimalkan usaha, baik dari sisi waktu, usaha, biaya, maupun risiko (Flavián et al., 2019, 2020; Yadav \& Pavlou, 2014). Dengan demikian, pemahaman karakteristik psikografi konsumen dalam melakukan webrooming diperlukan untuk meningkatkan strategi segmentasi pasar (Kang, 2018).

Konsumen telah terbiasa berinteraksi menggunakan cara online dan offline dalam proses mencari informasi tentang produk dan menggunakan minimal dua channel dalam melakukan pembelian produk (Flavián et al., 2019). Apalagi ketika konsumen ingin melakukan pembelian dengan keterlibatan tinggi (high involvement), maka konsumen akan melakukan riset online selama kurang lebih sebulan sebelum akhirnya melakukan pembelian secara online (Flavián et al., 2020). Suatu barang yang memerlukan tingkat keterlibatan konsumen tinggi membutuhkan informasi yang relatif lebih banyak dan kadang melelahkan bagi konsumen apalagi tanpa bantuan informasi dari internet. Dari uraian tersebut, penelitian ini merumuskan hipothesis kesatu (H1) sebagai berikut:

\section{H1: Webrooming berpengaruh signifikan terhadap confident.}

\section{Confident}

Confident adalah kondisi jiwa ketika seseorang merasa yakin atas penilaian terhadap suatu benda, brand, atau ketika berada dalam situasi berbelanja (Flavián et al., 2019; Heitmann, Lehmann, \& Herrmann, 2007). Dalam fase sebelum pemilihan produk, confident diartikan sebagai keyakinan yang membawa pada keputusan pembelian, yaitu keyakinan yang akan membawa kepada sebuah keputusan akhir yang tidak dapat diubah meskipun muncul informasi lain (Flavián et al., 2019). Konsumen melakukan webrooming untuk mengambil manfaat melalui internet guna mencari sebanyak-banyaknya informasi sebelum mereka melakukan pembelian agar risiko yang dihadapi minimal. Hal tersebut dapat meningkatkan perasaan percaya diri (confident) dalam proses pencarian informasi.

Konsumen berusaha menimimalkan ketidakpastian dalam berbelanja dengan melakukan webrooming, yaitu usaha konsumen untuk meningkatkan confident atas apa yang dilakukan dan dibeli, sehingga konsumen merasa memiliki banyak opsi, bebas memilih, dan tidak merasa dikendalikan oleh siapa pun (Flavián et al., 2019). Webrooming dapat meningkatkan consumer purchase experience, choice, search process satisfaction, dan choice confident (Flavián et al., 2016). Webrooming merupakan salah satu kegiatan yang dapat meningkatkan rasa percaya diri konsumen. Dengan melakukan webrooming, pengetahuan dan preferensi konsumen terhadap produk akan meningkat, yaitu menurunkan kesenjangan informasi dan meningkatkan kontrol terhadap proses pembelian (Flavián et al., 2019). Seseorang yang semakin percaya diri terhadap keputusan yang diambil, maka ia akan semakin suka terhadap pengalaman yang pernah dilakukannya, sehingga hal itu akan membawa perasaan puas (Heitmann et al., 2007).

Ketika kosumen merasa percaya diri dan yakin atas produk yang dipilihnya, maka ia merasa paham mengenai produk yang dibelinya tersebut. Kepuasan dalam diri konsumen akan meningkat atas proses yang dilakukan sebelumnya, karena ia telah mencari informasi 
mengenai produk yang ingin dibeli sebelumnya. Dari uraian tersebut, penelitian ini merumuskan hipotesis kedua (H2) sebagai berikut:

\section{H2: Confident berpengaruh signifikan terhadap search process satisfaction.}

\section{Smart Shopping Feeling}

Konsumen merasa dirinya cerdas, karena mereka telah meluangkan waktu dan tenaga untuk mencari dan memperoleh informasi terkait produk yang akan dibeli guna mendapatkan harga yang lebih murah, kualitas yang lebih baik, dan keuntungan lainnya. Sebelumnya, smart shopping feeling hanya dihubungkan dengan perasaan cerdas ketika konsumen mendapatkan harga yang paling murah, sehingga konsumen merasa menang ketika menemukan harga paling murah. Namun, seiring perkembangan zaman, smart shopping feeling bukan hanya permasalahan harga, tetapi bisa juga dari segi kualitas dan manfaat hedon lainnya (Flavián et al., 2019). Smart shopping feeling adalah kepercayaan konsumen bahwa mereka berada dalam kondisi mampu menghemat waktu, uang, tenaga, dan mendapatkan hasil yang maksimal dalam berbelanja.

Pada penelitian sebelumnya, smart shopping feeling apabila diartikan bahwa ketika konsumen mampu meminimalkan pengeluaran uang, waktu, energi, dan memaksimalkan hasil yang dapat diperoleh (Atkins \& Kim, 2012; Flavián et al., 2020). Smart shopping feeling banyak dikaitkan dengan aspek emosional yang berhubungan dengan ego dan semangat untuk mendapatkan outcome atau hasil yang paling baik dari berbelanja yang dilakukan konsumen, seperti mendapatkan harga yang lebih murah atau mendapatkan diskon (Flavián et al., 2020).

Dengan adanya pilihan belanja online dan offline, konsumen dapat meningkatkan pengalaman berbelanja untuk lebih meningkatkan kontrol dari pengalaman berbelanja yang mereka rasakan tersebut dan meningkatnya negosiasi yang dapat dilakukan oleh konsumen terhadap perusahaan (Flavián et al., 2020; Rodríguez-Torrico, Cabezudo, \& Martín, 2017). Terkadang, kosumen melakukan pencarian informasi online ketika berada di toko offline untuk membandingkan harga, promo, dan sebagainya. Hal itu dilakukan konsumen agar mereka menjadi smart shopper (Flavián et al., 2020). Webrooming dapat membuat konsumen merasa cerdas (smart shopping feeling). Informasi aktual yang tersedia di website dapat membantu kosumen untuk menentukan pilihan yang baik dan benar, yaitu konsumen akan merasa cerdas dan tidak merasa buta atas produk yang akan dibeli pada akhirnya. Hal itu juga mempengaruhi hubungan antara konsumen dan perusahaan, karena dapat meminimalkan kesenjangan informasi antara kedua pihak (Flavián et al., 2019).

Perasaan cerdas berbelanja timbul, ketika kosumen merasa bertanggung jawab untuk mendapatkan outcome yang benar dan tepat dalam berbelanja dan akhirnya ia memilih melakukan webrooming untuk mendapatkan hasil berbelanja yang tepat dengan mendatangi gerai offline. Ketika konsumen melakukan webrooming, ia akan merasa lebih memiliki kontrol terhadap barang yang akan dibeli (Flavián et al., 2019). Konsumen yang merasa bertanggung jawab dalam pembelian memiliki smart shopping feeling dan membawanya kepada hasil positif dari pengalaman berbelanja. Contohnya, kepuasan konsumen dalam berbelanja membawanya kepada perasaan smart shopping feeling yang berimbas kepada 
search process satisfaction dalam webrooming (Darke \& Dahl, 2003; Flavián et al., 2019; Schindler, 1998).

Pada era omnichannel dan multichannel yang erat hubungannya dengan webrooming, konsumen merasa lebih mampu mengontrol apa yang akan mereka beli dan mengetahui tentang apa yang akan dibeli dibandingkan salesperson yang dapat meningkatkan smart shopping feeling mereka. Smart shopping feeling dapat berpengaruh terhadap kepuasan konsumen dan pengalaman konsumen juga akan membentuk loyalitas dan hubungan jangka panjang konsumen dengan perusahaan (Flavián et al., 2020; Lemon \& Verhoef, 2016). Dari uraian tersebut, penelitian ini merumuskan hipotesis ketiga $(\mathrm{H} 3)$ dan keempat $(\mathrm{H} 4)$ yaitu:

\section{H3: Webrooming berpengaruh signifikan terhadap smart shopping feeling.}

\section{H4: Smart shopping feeling berpengaruh signifikan terhadap search process satis- faction.}

\section{User-generated Content}

Sebanyak $84 \%$ generasi milenial biasa mengandalkan konten dari media sosial tentang produk dalam keputusan pembelian mereka, sedangkan hanya $70 \%$ generasi baby boomers yang menggunakan konten media sosial sebagai dasar keputusan pembeliannya. Generasi milenial cenderung lebih percaya terhadap konten dan rekomendasi yang diberikan oleh orang asing daripada teman dan keluarga mereka sendiri (Kang, 2018). Konten tentang produk secara tekstual dan visual yang dipublikasikan oleh pengguna media sosial mempengaruhi sikap dan intensi konsumen terhadap brand (Herrero, Martín, \& Garcia-De los Salmones, 2017). User-generated content adalah konten media yang dihasil-kan oleh pengguna publik atau masyarakat dalam bentuk media online, seperti foto, review, video, podcast, konten forum, komen, dan konten blog yang dihasilkan, diedarkan, dan dikonsumsi oleh pengguna publik (Kang, 2018).

Konten yang dibuat oleh pengguna dan dikombinasikan dengan strategi pemasaran oleh perusahaan akan menjadikan daya tarik tersendiri bagi konsumen untuk mendapatkan awareness, bahkan penjualan produk untuk konsumen (Kang, 2018). User-generated content berbeda dari word of mouth (WOM). Word of mouth dilakukan oleh orang yang mungkin belum pernah membeli suatu produk, tetapi WOM berpotensi membahas produk tersebut, baik secara lisan, tulisan, pesan pribadi, maupun media sosial, sedangan usergenerated content dilakukan oleh konsumen yang sudah pernah membeli atau mendapatkan produk dan membuat konten mengenai produk yang dibelinya dan diposting di media sosial, bukan melalui pesan pribadi atau secara lisan (Daugherty et al., 2008).

Webrooming dapat meningkatkan penciptaan user-generated content melalui media sosial atau pun media online lainnya. Konsumen yang ingin mencari informasi melalui user-generated content akan terpengaruh untuk melakukan user-generated content juga. Web-roomers akan mencari informasi mengenai produk melalui media sosial, konten, dan komentar yang dipengaruhi oleh user-generated content. Konten yang dihasilkan oleh usergenerated content lebih dipercaya oleh konsumen yang melakukan webrooming, karena mereka menganggap bahwa user-generated content lebih dapat dipercaya dan apa adanya, 
khususnya untuk konten berupa komentar, foto, dan video secara acak tentang produk (Kang, 2018; Oum \& Han, 2011).

Beberapa alasan konsumen melakukan webrooming melalui pembuatan konten di media sosial adalah upaya untuk membantu konsumen lain agar mendapatkan informasi, terbantu seperti yang dialami sebelumnya, dan memberikan rekomendasi. Selain itu, konsumen membuat konten di media sosial untuk mengingat kembali apa yang dialami sebelumnya (Wilson, Murphy, \& Fierro, 2012). Oleh karena itu, ketika sebelumnya konsumen merasa pernah terbantu karena melakukan webrooming, maka kecenderungan untuk melakukan user-generated content akan semakin tinggi. Salah satu alasan konsumen melakukan user-generated content adalah untuk mencocokkan perasaan, persepsi, dan dukungan sosial (Kang, 2018). Membangun komunikasi dengan orang lain dapat meningkatkan pemahaman atas apa yang terjadi dan kenapa hal tersebut terjadi, atau dengan kata lain, hal itu dapat meminimalkan kesalahpahaman pada diri konsumen (Berger, 2014). Ketika kesalahpahaman diminimalkan, maka tingkat kepuasan atas apa yang telah dialami akan meningkat (Colicev et al., 2019).

Ketika konsumen memperoleh pengalaman negatif, maka emosi negatif akan muncul dalam dirinya. Ketika ia mendapatkan dukungan sosial dari orang lain, maka hal itu dapat meredakan emosi negatif dalam dirinya (Daugherty et al., 2008). Sebaliknya, ketika konsumen merasakan hal postif atas apa yang dialaminya, ia akan membaginya dengan orang lain, maka perasaan positif dalam diri konsumen semakin meningkat. Hal itu akan meningkatkan perasaan puas atas apa yang dialami konsumen (Berger, 2014). Berbagi pengalaman dengan orang lain, dalam hal membuat konten dan membaginya di media sosial dapat mendukung keputusan yang telah diambil oleh konsumen sebelumnya. Berbagi pengalaman yang baik dapat meningkatkan efek dan perasaan positif atas apa yang dialami oleh konsumen. Bahkan, kondisi itu dapat memberikan efek positif terhadap hal-hal di luar pengalaman tersebut. Dalam hal ini, user-generated content dapat membantu meminimalkan jarak antara harapan dan pengalaman aktual yang dialami (Colicev et al., 2019). Dari uraian tersebut, penelitian ini merumuskan hipotesis kelima (H5) dan keenam (H6) sebagai berikut:

\section{H5: Webrooming berpengaruh signifikan terhadap user-generated content.}

\section{H6: User-generated content berpengaruh signifikan terhadap search process satis- faction.}

\section{Search Process Satisfaction}

Search process satisfaction adalah kepuasan terhadap proses pencarian informasi secara aktual (Flavián et al., 2019; Kozup et al., 2003). Perasaan puas yang dirasakan konsumen bukan hanya didapatkan dari barang yang dibeli, tetapi dari pengalaman yang didapatkan selama proses berbelanja. Perasaan puas terhadap pengalaman berbelanja dan proses pengambilan keputusan dalam memilih barang membawa kepuasan terhadap penggunaan barang setelah proses pembelian (Heitmann et al., 2007). Rasa puas adalah salah satu kunci yang harus diperhatikan dalam manajemen pengalaman pelanggan untuk meningkatkan dan mempertahankan hubungan jangka panjang dengan mereka (Flavián et al., 
2019). Dalam 30 tahun ini, kepuasan menjadi salah satu konsep penting dalam dunia marketing. Penelitian terdahulu menyatakan bahwa pengalaman dalam pengambilan keputusan berhubungan dengan kepuasan (Heitmann et al., 2007).

Konsumen yang melakukan webrooming merasa lebih puas daripada yang tidak melakukan webrooming, karena mereka merasa benar dalam mengambil keputusan (Flavián et al., 2019). Perasaan puas yang muncul dalam proses pencarian informasi (search process satisfaction), karena konsumen merasa lebih percaya diri dan merasa lebih cerdas apabila mereka melakukan webrooming sebelum pembelian produk (Flavián et al., 2019). Webrooming memiliki pengaruh positif terhadap search process satisfaction, yaitu konsumen yang melakukan webrooming mengambil manfaat dengan adanya internet untuk mencari sebanyak mungkin informasi sebelum mereka melakukan pembelian. Tindakan itu bertujuan untuk meminimalkan risiko yang dihadapi, sehingga perasaan percaya diri akan meningkat dalam proses pencarian informasi.

Webrooming meningkatkan purchase experience konsumen, choice, search process satisfaction, dan confident (Flavián et al., 2016). Ketersediaan informasi yang beragam dan informatif di internet membuat konsumen merasa puas dengan proses pencarian informasi. Rasa puas adalah salah satu kunci untuk meningkatkan dan mempertahankan hubungan panjang dengan pelanggan (Flavián et al., 2019). Dari uraian tersebut, penelitian ini merumuskan hipotesis ketujuh (H7) sebagai berikut:

\section{H7: Webrooming berpengaruh signifikan terhadap search process satisfaction.}

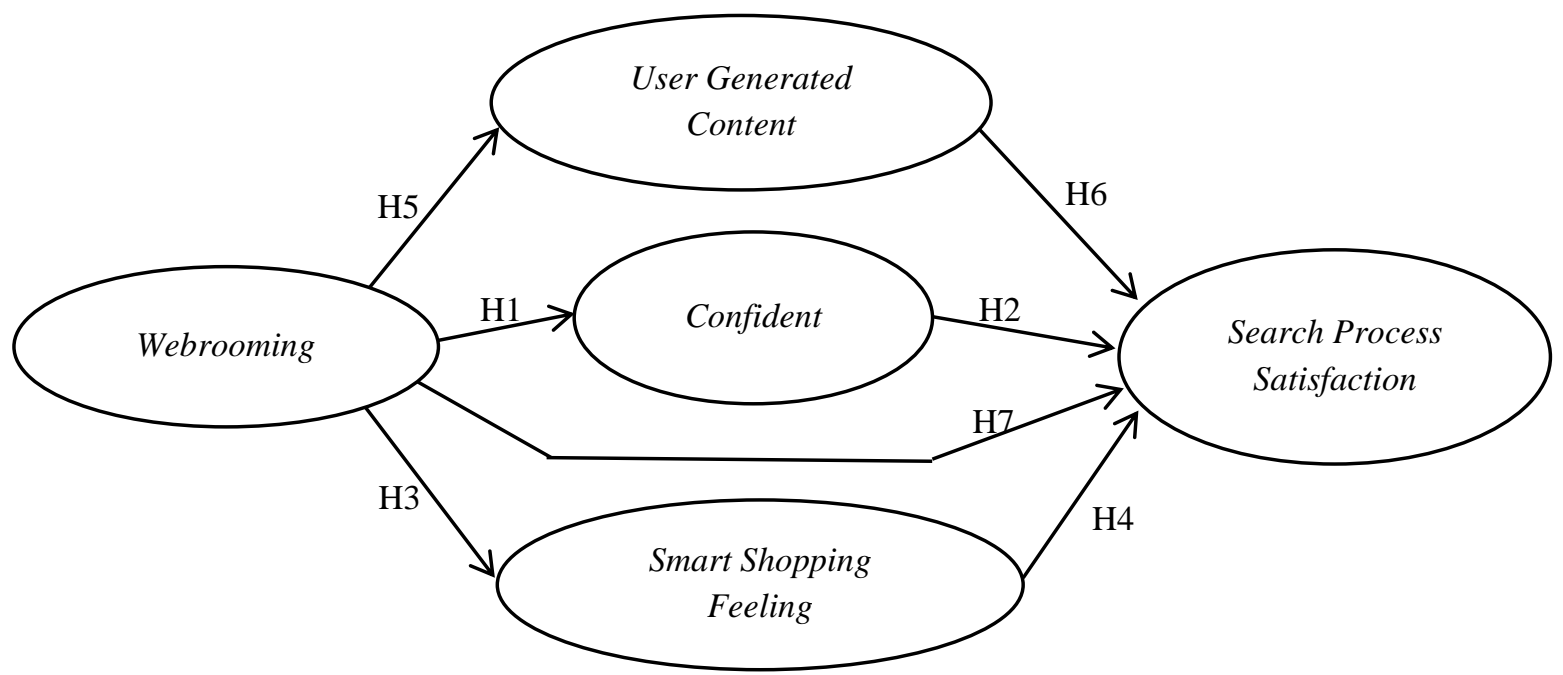

Gambar 1. Model Penelitian

\section{Model Penelitian}

Webrooming merupakan perilaku konsumen dalam proses berbelanja, sehingga penelitian ini menguji pengaruh webrooming terhadap search process satisfacion dan juga pengaruh webrooming terhadap confident, smart shopping feeling, dan user-generated content. Selain itu, penelitian ini akan menguji pengaruh user-generated content, confident, 
dan smart shopping feeling terhadap search process satisfaction. Hubungan antarvariabel yang diuji dalam penelitian ini ditunjukkan pada Gambar 1.

\section{METODE PENELITIAN}

Penelitian ini menggunakan metode kuantitatif dengan meneliti pada populasi atau sampel tertentu, mengumpulkan data menggunakan instrumen penelitian, analisis data bersifat kuantitatif/statistik yang bertujuan untuk menguji hipotesis yang telah ditetapkan. Penelitian ini untuk mengetahui pengaruh antara satu variabel dengan variabel lainnya. Pengumpulan data menggunakan kuesioner yang disebarkan kepada sampel dari populasi yang telah ditetapkan.

\section{Populasi dan Sampel Penelitian}

Populasi dalam penelitian ini adalah pengguna media sosial yang pernah melakukan webrooming (mencari produk secara online dan membeli produk tersebut di gerai offline). Sampel dalam penelitian ini adalah sebagian dari populasi yang berbelanja produk kecantikan dalam enam bulan terakhir, karena menurut Bruno dalam Syah (2010) daya ingat seseorang akan bertahan sampai dengan enam bulan setelah ingatan tersebut hilang secara perlahan. Menurut penelitian yang dilakukan oleh Zap Beauty Index, usia pengguna produk kecantikan di Indonesia dimulai dari usia 13 tahun atau lebih (Putri, 2020). Namun, sampel pada penelitian tersebut berusia lebih dari atau sama dengan 17 tahun hingga 45 tahun, karena mereka telah dikategorikan dewasa mulai usia 18 tahun. Meskipun penelitian ini berkaitan dengan produk kecantikan, penelitian ini tidak membedakan jenis kelamin dan responden dapat diisi, baik oleh laki-laki maupun perempuan, karena penggunaan produk kecantikan saat ini sudah tidak lagi memandang jenis kelamin, tebukti dengan banyaknya produk kecantikan khusus laki-laki mulai dari high class brand, seperti Channel Boy sampai dengan middle class brand, seperti Unilever yang memperluas pasar produk kecantikan mereka untuk kaum laki-laki (Mangkuto, 2019).

\section{Instrumen Pengumpulan Data}

Sebagai screening awal, penelitian ini melakukan wawancara dengan beberapa pengguna media sosial yang yang berusia lebih dari atau sama dengan 17 tahun dan menanyakan apakah mereka pernah melakukan webrooming. Metode pengumpulan data menggunakan survei lapangan dengan cara menyebarkan kuesioner secara online kepada responden terpilih menggunakan google forms. Metode penentuan sampel dalam penelitian ini menggunakan non-probability sampling dengan teknik purposive sampling, yaitu teknik pengambilan sampel dengan syarat memenuhi kriteria tertentu. Kriteria purposive sampling dalam penelitian ini adalah pengguna media sosial yang pernah melakukan webrooming (mencari produk secara online dan membeli produk di gerai offline) dan telah berusia lebih dari atau sama dengan 17 tahun. Pertanyaan-pertanyaan tentang variabel-variabel yang diuji dalam penelitian ini didasarkan pada definisi operasional dan indikator pada Tabel 1. 
Tabel 1. Variabel Penelitian

\begin{tabular}{|c|c|c|}
\hline Variabel & Definisi Operasional & Indikator/referensi \\
\hline Webrooming & $\begin{array}{l}\text { Perilaku dalam proses pembelian, ketika } \\
\text { konsumen melakukan tahap pencarian informasi } \\
\text { menggunakan internet, baik di media sosial } \\
\text { maupun website sebelum melakukan pembelian } \\
\text { di toko offline dalam berbelanja produk (Flavian } \\
\text { et al., 2016). }\end{array}$ & $\begin{array}{l}\text { - Apakah sering melakukan } \\
\text { webrooming. } \\
\text { - Mencari informasi produk } \\
\text { sebelum berbelanja produk. } \\
\text { - Ketika mencari informasi produk } \\
\text { secara online, setelah itu } \\
\text { memutuskan membeli produk } \\
\text { secara offline. } \\
\text { (Arora et al., 2018) }\end{array}$ \\
\hline Confident & $\begin{array}{l}\text { Suatu keadaan ketika konsumen merasa yakin } \\
\text { akan situasi berbelanja yang dialami dan proses } \\
\text { yang dilalui (Flavián et al., 2019). }\end{array}$ & $\begin{array}{l}\text { - Merasa mudah menemukan } \\
\text { produk yang cocok. } \\
\text { - Percaya diri akan menemukan } \\
\text { produk kecantikan yang cocok. } \\
\text { - Yakin akan menemukan produk } \\
\text { kecantikan yang dapat memenuhi } \\
\text { kebutuhan. } \\
\text { (Heitmann } \text { et al., 2007) }\end{array}$ \\
\hline $\begin{array}{l}\text { Smart shopping } \\
\text { feeling }\end{array}$ & $\begin{array}{l}\text { Perasaan cerdas yang dirasakan konsumen, } \\
\text { karena ia telah menghemat biaya, waktu, dan } \\
\text { tenaga dalam proses belanjanya (Flavián } \text { et al., } \\
\text { 2019). }\end{array}$ & $\begin{array}{l}\text { - Menghemat waktu. } \\
\text { - Menghemat biaya. } \\
\text { - Menghemat sumberdaya. } \\
\text { (Flavián et al., 2019) }\end{array}$ \\
\hline $\begin{array}{l}\text { User-generated } \\
\text { content }\end{array}$ & $\begin{array}{l}\text { Aktivitas konsumen membuat konten produk } \\
\text { yang dibelinya (Kang, 2018). }\end{array}$ & $\begin{array}{l}\text { - Membagi pengalaman. } \\
\text { - Mengekspresikan pengalaman. } \\
\text { - Menunjukkan pengetahuan. } \\
\text { - Bebagi dan membandingkan } \\
\text { dengan orang lain. } \\
\text { (Wilson et al., 2012) }\end{array}$ \\
\hline $\begin{array}{l}\text { Search process } \\
\text { satisfaction }\end{array}$ & $\begin{array}{l}\text { Konsumen merasa puas terhadap proses } \\
\text { pencarian informasi tentang barang yang akan } \\
\text { dibelinya (Flavián et al., 2019). }\end{array}$ & $\begin{array}{l}\text { Puas dengan kemudahan } \\
\text { pencarian informasi. } \\
\text { - Proses pencarian informasi } \\
\text { menarik. } \\
\text { - Puas dengan ketersediaan } \\
\text { informasi. } \\
\text { - Merasa akan membuat keputusan } \\
\text { yang tepat. } \\
\text { - Puas dengan pengalaman } \\
\text { pencarian informasi. } \\
\text { (Flavián } \text { et al., 2016) }\end{array}$ \\
\hline
\end{tabular}

Sumber: Referensi terkait.

\section{Metode Analisis Data}

Metode analisis data yang digunakan dalam penelitian ini adalah analisis kuantitatif dengan menggunakan model SEM (Structural Equation Modeling) dengan bantuan program AMOS (Analysis of Moment Structures) versi 26 atau model persamaan struktural. SEM dapat didiskripsikan sebagai suatu analisis yang menggabungkan pendekatan analisis faktor (factor analysis), model struktural (structural model), dan analisis jalur (path analy- 
sis) (Sugiyono, 2010). Menurut Ghozali (2011), SEM merupakan gabungan dari metode statistik yang terpisah, yaitu analisis faktor (factor analysis) dan model persamaan simultan (simultaneous equation modeling). Model penelitian yang dirancang akan digambarkan dengan menggunakan AMOS versi 26 yang digunakan sebagai pendekatan umum analisis data dalam SEM.

\section{HASIL DAN PEMBAHASAN}

\section{Analisis Profil Responden}

Responden dalam penelitian ini berjumlah 166 orang, seluruh responden dalam penelitian ini adalah konsumen produk kecantikan dan pernah melakukan pencarian informasi produk kecantikan melalui internet (secara online), sebelum membeli produk tersebut di toko fisik (secara offline) atau yang disebut dengan webrooming. Profil responden diklasifikasikan berdasar usia, waktu terakhir mencari informasi produk kecantikan di internet, dan waktu terakhir membeli produk kecantikan. Klasifikasi yang dilakukan dalam penelitian ini bertujuan untuk mengetahui gambaran responden sebagai obyek penelitian dengan jelas. Berdasarkan jenis kelamin, responden dalam penelitian ini terdiri atas 148 orang perempuan atau $89,2 \%$, sedangkan laki-laki sebanyak 18 orang atau $10,8 \%$.

Tabel 2. Frekuensi Pencarian Informasi mengenai Produk Kecantikan di Internet dan Frekuensi Pembelian Produk Kecantikan

\begin{tabular}{lcccc}
\hline \multirow{1}{*}{ Periode waktu } & \multicolumn{2}{c}{$\begin{array}{c}\text { Pencarian Informasi Produk } \\
\text { Kecantikan di Internet }\end{array}$} & \multicolumn{2}{c}{$\begin{array}{c}\text { Pembelian Produk } \\
\text { Kecantikan }\end{array}$} \\
& Frekuensi & Persentase & Frekuensi & Persentase \\
\hline 1 hari lalu & 21 & 12,7 & 13 & 7,8 \\
\hline 1 minggu lalu & 37 & 22,3 & 20 & 12,0 \\
\hline 1 bulan lalu & 76 & 45,8 & 84 & 50,6 \\
\hline 6 bulan lalu & 32 & 19,3 & 49 & 29,5 \\
\hline Jumlah & $\mathbf{1 6 6}$ & $\mathbf{1 0 0 , 0}$ & $\mathbf{1 6 6}$ & $\mathbf{1 0 0 , 0}$ \\
\hline
\end{tabular}

Sumber: Pengumpulan data primer (2021).

\section{Uji Validitas Instrumen Penelitian}

Uji validitas konvergen adalah pengujian indikator apakah instrumen memiliki proporsi variance yang tinggi atau tidak melalui penilaian loading factor yang merefleksikan hubungan antara masing- masing butir pernyataan dengan variabel laten. Uji validitas konvergen tersebut dianggap memenuhi kriteria apabila loading factor $\geq 0,50$ (Ghozali, 2011). Pada penelitian ini hasil uji validitas konvergen menunjukkan nilai loading factor seluruh butir lebih besar dari 0,5. Hasil tersebut menunjukkan bahwa seluruh butir instrumen dinyatakan valid dan dapat digunakan untuk analisis atau penelitian lainnya. 
Tabel 3. Hasil Uji Validitas

\begin{tabular}{|c|c|c|c|c|}
\hline & & Items & Estimate & Keterangan \\
\hline WR1 & $\leftarrow$ & Webrooming & 0,804 & Valid \\
\hline WR2 & $\leftarrow$ & Webrooming & 0,866 & Valid \\
\hline WR3 & $\leftarrow$ & Webrooming & 0,826 & Valid \\
\hline $\mathrm{C} 1$ & $\leftarrow$ & Confident & 0,737 & Valid \\
\hline $\mathrm{C} 2$ & $\leftarrow$ & Confident & 0,753 & Valid \\
\hline $\mathrm{C} 3$ & $\leftarrow$ & Confident & 0,874 & Valid \\
\hline $\mathrm{S} 1$ & $\leftarrow$ & Smart shopping feeling & 0,938 & Valid \\
\hline $\mathrm{S} 2$ & $\leftarrow$ & Smart shopping feeling & 0,936 & Valid \\
\hline S3 & $\leftarrow$ & Smart shopping feeling & 0,765 & Valid \\
\hline UGC1 & $\leftarrow$ & User-generated content & 0,910 & Valid \\
\hline UGC2 & $\leftarrow$ & User-generated content & 0,983 & Valid \\
\hline UGC3 & $\leftarrow$ & User-generated content & 0,987 & Valid \\
\hline UGC4 & $\leftarrow$ & User-generated content & 0,891 & Valid \\
\hline UGC5 & $\leftarrow$ & User-generated content & 0,981 & Valid \\
\hline SAT1 & $\leftarrow$ & Search process satisfaction & 0,897 & Valid \\
\hline SAT2 & $\leftarrow$ & Search process satisfaction & 0,910 & Valid \\
\hline SAT3 & $\leftarrow$ & Search process satisfaction & 0,829 & Valid \\
\hline SAT4 & $\leftarrow$ & Search process satisfaction & 0,943 & Valid \\
\hline SAT5 & $\leftarrow$ & Search process satisfaction & 0,980 & Valid \\
\hline
\end{tabular}

Sumber: Olah data primer menggunakan AMOS versi 26.

\section{Uji Reliabilitas Instrumen Penelitian}

Uji reliabilitas digunakan untuk mengetahui apakah instrumen penelitian ini dapat diandalkan dan tetap konsisten apabila pengukuran tersebut digunakan ulang. Uji reliabilitas dilakukan dengan menggunakan uji construct reliability, yaitu menguji keandalan dan konsistensi data. Reliabilitas memenuhi kriteria apabila construct reliability lebih besar dari 0,70. Berdasarkan Tabel 4, seluruh variabel dalam penelitian ini memiliki nilai construct reliability lebih besar dari 0,70 , sehingga semua variabel yang diuji dalam penelitian ini memiliki reliabilitas yang baik.

Tabel 4. Uji Reliabilitas

\begin{tabular}{lcc}
\hline \multicolumn{1}{c}{ Variabel } & Reliabilitas Konstruk & Keterangan \\
\hline Webrooming & 0,967 & Reliabel \\
\hline Confident & 0,909 & Reliabel \\
\hline Smart Shopping Feeelings & 0,911 & Reliabel \\
\hline User-generated Content & 0,893 & Reliabel \\
\hline Search Process Satisfaction & 0,973 & Reliabel \\
\hline
\end{tabular}

Sumber: Olah data primer menggunakan AMOS versi 26.

\section{Uji Kesesuaian Model}

Pada tahap analisis kesesuaian terhadap full structural model, model penelitian ini dilakukan evaluasi menggunakan goodness of fit index. Hasil perhitungan nilai-nilai indeks 
pada goodness of fit yang dihasilkan oleh model penelitian ini ditunjukkan pada Tabel 5. Hasil pengujian goodness of fit menunjukkan bahwa model SEM pada penelitian ini cukup baik dan dapat diterima, karena hasilnya menunjukkan empat uji kesesuaian model penelitian ini dinyatakan fit. Dengan demikian, analisis uji hipotesis lebih lanjut dapat dilakukan.

Tabel 5. Uji Kesesuaian Model

\begin{tabular}{lrcl}
\hline \multicolumn{1}{c}{ Goodness of Fit } & Cut-off & Hasil Uji Model & Keterangan \\
\hline Probability level & $\geq 0,05$ & 0,000 & Marjinal \\
\hline GFI & $\geq 0,9$ & 0,855 & Marjinal \\
AGFI & $\geq 0,8$ & 0,807 & Fit \\
\hline TLI & $\geq 0,90$ & 0,914 & Fit \\
\hline CFI & $\geq 0,90$ & 0,928 & Fit \\
\hline RMSEA & $\leq 0,08$ & 0,078 & Marjinal \\
CMIN/DF & $\leq 2,0$ & 2,500 & Marjinal \\
RMR & $\leq 0,05$ & 0,048 & Fit \\
\hline
\end{tabular}

Sumber: Olah data primer menggunakan AMOS versi 26.

\section{Pengujian Hipotesis dan Pembahasan}

Berdasarkan hasil uji hipotesis berdasarkan model penelitian yang ditunjukkan pada Tabel 6 dengan nilai signifikansi 5\%, maka enam hipotesis yang diuji menunjukkan pengaruh signifikan dan satu hipotesis terbukti tidak signifikan. Hasil pengujian hipotesis diuraikan sebagai berikut ini.

Tabel 6. Hasil Pengujian Hipotesis

\begin{tabular}{clccc}
\hline Hn & \multicolumn{1}{c}{ Hipotesis } & c.r & Prob & Keterangan \\
\hline H1 & Webrooming Terhadap Confident & 6,592 & 0,000 & Signifikan \\
\hline H2 & Confident Terhadap Serach Proccess Satisfaction & 5,145 & 0,000 & Signifikan \\
\hline H3 & Webrooming Terhadap Smart Shopping Feeling & 6,568 & 0,000 & Signifikan \\
\hline H4 & $\begin{array}{l}\text { Smart Shopping Feeling Teradap Serach Process } \\
\text { Satisfaction }\end{array}$ & 3,893 & 0,000 & Signifikan \\
\hline H5 & Webrooming Terhadap User-generated Content & 7,877 & 0,000 & Signifikan \\
\hline H6 & $\begin{array}{l}\text { User-generated Content Terhadap Search Process } \\
\text { Satisfaction }\end{array}$ & $-0,451$ & 0,652 & Tidak signifikan \\
\hline H7 & Webrooming Terhadap Search Process Satisfaction & 4,913 & 0,000 & Signifikan \\
\hline Keterangan
\end{tabular}

Keterangan: c.r. $=$ critical ratio $;$ Prob $=$ probability.

Sumber: Olah data primer menggunakan AMOS versi 26.

\section{a. Pengaruh Webrooming terhadap Confident}

Berdasarkan pengujian hipotesis kesatu (H1) pada Tabel 6, webrooming berpengaruh positif dan signifikan terhadap confident dengan hasil pengujian c.r 6,592 dan prob 0,000. Pengaruh tersebut terjadi, apabila konsumen melakukan webrooming ketika berbelanja produk kecantikan, maka rasa percaya diri (confident) konsumen akan meningkat. Dengan informasi mengenai produk kecantikan yang diperoleh sebelum berbelanja, maka keperca- 
yaan diri atas produk kecantikan yang akan dibeli akan meningkat. Hasil penelitian ini menjelaskan bahwa konsumen berusaha menimimalkan ketidakpastian dalam berbelanja produk kecantikan, salah satunya melalui tindakan webrooming. Konsumen merasa memiliki banyak opsi, bebas memilih, dan tidak merasa dikendalikan oleh siapa pun. Hasil penelitian ini didukung oleh penelitian (Flavián et al., 2019), yaitu ketika konsumen melakukan webrooming saat ia berbelanja, maka tingkat kepercayaan dirinya (confident) dalam mengambil keputusan semakin tinggi.

\section{b. Pengaruh Confident terhadap Search Proccess Satisfaction}

Berdasarkan pengujian hipotesis kedua (H2) yang ditunjukkan pada Tabel 6, confident terbukti berpengaruh positif dan signifikan terhadap search process satisfaction dengan hasil pengujian c.r 5,145 dan prob 0,000. Pengaruh tersebut terjadi, apabila konsumen merasa confident atas produk kecantikan yang dibelinya, sehingga rasa puas dalam pencarian informasi mengenai produk kecantikan dapat meningkat. Ketika konsumen memahami produk kecantikan yang akan dibelinya, maka timbul rasa percaya diri tersebut. Selanjutnya, perasaan percaya diri dalam diri konsumen meningkat, maka perasaan puas juga akan meningkat dalam dirinya. Semakin percaya diri seseorang terhadap keputusan yang diambil, maka ia semakin suka terhadap pengalaman yang pernah dilakukannya. Hasil tersebut nantinya akan membawa pada kondisi perasaan yang puas (Heitmann et al., 2007). Hasil penelitian ini didukung oleh penelitian sebelumnya oleh (Flavián et al., 2019, 2020).

\section{c. Pengaruh Webrooming terhadap Smart Shopping Feeling}

Berdasarkan pengujian hipotesis ketiga (H3) yang ditunjkkan pada Tabel 6, webrooming berpengaruh positif dan signifikan terhadap smart shopping feeling dengan hasil pengujian c.r 6,568 dan prob 0,000. Pengaruh tersebut terjadi, apabila konsumen melakukan webrooming saat berbelanja produk kecantikan, maka perasaan cerdas dalam berbelanja (smart shopping feeling) konsumen akan meningkat. Ketika konsumen melakukan webrooming, ia akan mencari informasi produk kecantikan yang akan dibelinya sebanyakbanyaknya. Setidaknya, konsumen akan mencari informasi tentang lokasi penjualan produk, harga, spesifikasi produk sebelumnya, dan lain-lain. Dengan informasi tersebut, konsumen akan merasa lebih meluangkan waktu dan tenaga lebih sedikit, serta kemungkinan mendapatkan harga yang lebih murah berdasarkan informasi produk kecantikan yang ia miliki. Penelitian ini menjelaskan bahwa webrooming dapat membuat konsumen merasa cerdas (smart shopping feeling). Informasi aktual yang tersedia di website dapat membantu konsumen untuk menentukan pilihan yang baik dan benar, yaitu ia akan merasa cerdas atau tidak merasa buta pengetahuan atas produk kecantikan yang akan dibelinya (Flavián et al., 2019). Hasil penelitian ini selaras dengan penelitian sebelumnya oleh (Flavián et al., 2019, 2020) yang menyebutkan bahwa ketika konsumen melakukan webrooming ketika berbelanja, maka tingkat smart shopping feeling konsumen dalam mengambil keputusan semakin tinggi.

\section{d. Pengaruh Smart Shopping Feeling terhadap Search Process Satisfaction}

Berdasarkan pengujian hipotesis keempat (H4) yang ditunjukkan pada Tabel 6, smart shopping feeling berpengaruh positif dan signifikan terhadap search process satisfaction dengan hasil pengujian c.r 3,893 dan prob 0,000. Pengaruh tersebut terjadi, karena ketika 
konsumen merasa lebih cerdas dalam berbelanja produk kecantikan, maka rasa puas yang dirasakan konsumen akan meningkat. Ketika konsumen merasa dapat menghemat waktu, biaya, dan merasa benar dalam mengambil keputusan pembelian produk kecantikan, maka perasaan puas konsumen terhadap keterlibatannya, atau dalam hal ini adalah search process satisfaction, di dalam proses pencarian informasi akan meningkat. Hasil penelitian ini senada dengan penelitian sebelumnya oleh (Flavián et al., 2019; Lemon \& Verhoef, 2016) yang menemukan bahwa smart shopping feeling berpengaruh terhadap search process satisfaction.

\section{e. Pengaruh Webrooming Terhadap User-generated Content}

Berdasarkan pengujian hipotesis kelima (H5) yang ditunjukkan pada Tanel 6, webrooming terbukti berpengaruh positif dan signifikan terhadap user-generated content dengan hasil pengujian c.r 7,877 dan prob 0,000. Pengaruh tersebut terjadi, apabila konsumen melakukan webrooming ketika berbelanja produk kecantikan, maka kebiasaan konsumen menggunakan media digital dalam menerima dan membagi informasi akan membuatnya cenderung melakukan user-generated content. Ada beberapa alasan konsumen yang melakukan webrooming membuat konten produk kecantikan di media sosial. Salah satunya adalah keinginan membantu konsumen lain agar mendapatkan informasi produk kecantikan dengan lebih tepat dan terbantu seperti yang dialami sebelumnya, serta memberikan rekomendasi tentang suatu produk kecantikan. Selain itu, konsumen yang membuat konten di media sosial akan mengingat kembali apa yang ia alami sebelumnya (Wilson et al., 2012). Hasil penelitian ini didukung oleh penelitian sebelumnya oleh (Kang, 2018) yang menyatakan bahwa pengguna webrooming cenderung melakukan user-generated content.

\section{f. Pengaruh User-generated Content terhadap Search Process Satisfaction}

Berdasarkan pengujian hipotesis keenam (H6) yang ditunjukkan pada Tabel 6, usergenerated content tidak terbukti berpengaruh terhadap search process satisfaction dengan hasil pengujian c.r -0,451 dan prob 0,652. Penelitian ini membuktikan bahwa membuat konten di media sosial dapat mendukung keputusan yang telah diambil konsumen sebelumnya. Berbagi informasi dan pengalaman yang baik dapat meningkatkan efek dan perasaan positif atas apa yang dialami konsumen (Colicev et al., 2019). Pada umumnya, usergenerated content dapat meningkatkan perasaan puas atas apa yang dialami konsumen. Namun, hasil penelitian ini menunjukkan hasil yang berbeda, perilaku konsumen untuk membagi konten melalui jaringan internet (user-generated content) tidak mempengaruhi kepuasan dalam pencarian informasi (search process satisfaction). Hasil ini dapat terjadi karena alasan utama seseorang membuat konten melalui jaringan internet adalah keinginan berbagi, berinteraksi sosial, dan menjadi lebih dikenal (Daugherty et al., 2008), dan bukan untuk memperoleh kepuasan terhadap apa yang dilakukannya.

\section{g. Pengaruh Webrooming terhadap Search Process Satisfaction}

Berdasarkan pengujian hipotesis ketujuh (H7) yang ditunjukkan pada Tabel 6, webrooming terbukti berpengaruh positif dan signifikan terhadap search process satisfaction dengan hasil pengujian c.r 4,913 dan prob 0,000. Pengaruh tersebut terjadi, apabila konsumen melakukan webrooming ketika berbelanja produk kecantikan, sehingga kepuasan 
dalam proses pencarian informasi dapat meningkat. Sebelum berbelanja produk kecantikan, konsumen mencari informasi tentang produk tersebut melalui jaringan internet. Ketersediaan informasi di internet yang mudah, informatif, dan dua arah, membuat konsumen merasa puas dalam proses pencarian informasi produk kecantikan. Perilaku webrooming merasa lebih puas daripada yang tidak melakukan webrooming, karena mereka merasa lebih benar dalam mengambil keputusan. Perasaan puas dalam proses pencarian informasi (search process satisfaction), karena konsumen merasa lebih percaya diri dan lebih cerdas apabila sebelum berbelanja produk kecantikan, mereka melakukan webrooming terlebih dulu (Flavián et al., 2019). Penelitian ini didukung oleh penelitian sebelumnya oleh (Flavian et al., 2016; Flavián et al., 2019) yang menemukan bahwa webrooming dapat meningkatkan search process satisfaction.

\section{KESIMPULAN DAN SARAN}

Berdasarkan hasil temuan pada penelitian ini, webrooming berpengaruh positif secara langsung dan tidak langsung terhadap search process satisfaction. Hal ini menunjukkan semakin sering konsumen mengalami dan melakukan proses webrooming dalam berbelanja, maka semakin tinggi kepuasan konsumen dalam proses pencarian informasi saat ia berbelanja. Penelitian ini juga menemukan bahwa webrooming dapat meningkatkan rasa percaya diri, perasaan cerdas dalam berbelanja, dan juga meningkatkan keinginan konsumen untuk membuat konten tentang produk yang dibeli di media sosialnya.

Berdasarkan hasil penelitian ini, beberapa saran bagi para praktisi seperti pemasar adalah upaya lebih memperhatikan konten mengenai produk yang disampaikan melalui jaringan internet. Internet telah menjadi sumber informasi bagi konsumen sebelum ia berbelanja produk kecantikan. Sebagaimana internet menjadi sumber informasi bagi konsumen tentang produk, maka praktisi dapat memanfaatkan hal tersebut dengan memberikan stimulus kepada konsumen untuk membuat konten pula tentang produk dengan memperhatikan ketersediaan informasi yang cukup dan tepat melalui jaringan internet, serta memanfaatkan kebiasaan konsumen dalam mencari informasi mengenai produk di internet sebelum ia berbelanja dan kebiasaan konsumen pula dalam membuat konten di internet setelah berbelanja. Bagi para praktisi seperti pemasar, penelitian ini memberikan informasi bahwa webrooming memiliki pengaruh signifikan tehadap kepuasan pelanggan dalam proses pencarian informasi, meningkatkan rasa percaya diri mereka, munculnya perasaan cerdas dalam berbelanja, dan mendorong mereka untuk membuat konten mengenai produk di internet.

\section{DAFTAR REFERENSI}

Annur, C. M. (2019). Google Ungkap Pencarian tentang Kecantikan Naik 30\% Tahun Ini. Katadata, Digital, 19 Desember. Diakses tanggal 15 Januari 2021 di https://katadata.co.id/marthathertina/digital/5e9a4c3e10e69/google-ungkappencarian-tentang-kecantikan-naik-30-tahun-ini. 
Arora, S., \& Sahney, S. (2019). Examining Consumers' Webrooming Behavior: An Integrated Approach. Marketing Intelligence and Planning, 37(3), 339-354. https://doi.org/10.1108/MIP-05-2018-0152.

Atkins, K.G., \& Kim, Y-. K. (2012). Smart shopping: Conceptualization and Measurement. International Journal of Retail \& Distribution Management, 40(5), 360-375 https://doi.org/10.1108/09590551211222349.

Berger, J. (2014). Word of Mouth and Interpersonal Communication: A Review and Directions for Future Research. Journal of Consumer Psychology, 24(4), 586-607. https://doi.org/10.1016/j.jcps.2014.05.002.

Colicev, A., Kumar, A., \& O’Connor, P. (2019). Modeling the Relationship between Firm and User-generated Content and the Stages of the Marketing Funnel. International Journal of Research in Marketing, 36(1), 100-116. https://doi.org/10.1016/j.ijresmar.2018.09.005.

Darke, P. R., \& Dahl, D. W. (2003). Fairness and Discounts: The Subjective Value of a Bargain. Journal of Consumer Psychology, 13(3), 328-338. https://doi.org/10.1207/S15327663JCP1303_13.

Daugherty, T., Eastin, M. S., \& Bright, L. (2008). Exploring Consumer Motivations for Creating User-Generated Content. Journal of Interactive Advertising, 8(2), 16-25. https://doi.org/10.1080/15252019.2008.10722139.

Devinder, P. S. (2014). Online Shopping Motivations, Information Search, and Shopping Intentions in an Emerging Economy. East Asian Journal of Business Management, 4(3), 5-12. https://doi.org/10.13106/eajbm.2014.vol4.no3.5.

Flavian, C., Gurrea, R., \& Orús, C. (2016). Choice Confidence in the Webrooming Purchase Process: The Impact of Online Positive Reviews and the Motivation to Touch. Journal of Consumer Behaviour, 50(October), 35-50. https://doi.org/10.1002/cb.

Flavián, C., Gurrea, R., \& Orús, C. (2019). Feeling Confident and Smart with Webrooming: Understanding the Consumer's Path to Satisfaction. Journal of Interactive Marketing, 47, 1-15. https://doi.org/10.1016/j.intmar.2019.02.002.

Flavián, C., Gurrea, R., \& Orús, C. (2020). Combining Channels to Make Smart Purchases: The Role of Webrooming and Showrooming. Journal of Retailing and Consumer Services, 52(January), 1-11. https://doi.org/10.1016/j.jretconser.2019.101923.

Ghozali, I. (2011). Aplikasi Analisis Multivariate dengan Program SPSS. Semarang: Badan Penerbit Universitas Diponegoro.

Heitmann, M., Lehmann, D. R., \& Herrmann, A. (2007). Choice Goal Attainment and Decision and Consumption Satisfaction. Journal of Marketing Research, 44(2), 234250. https://doi.org/10.1509/jmkr.44.2.234.

Herrero, Á., Martín, H. S., \& Garcia-De los Salmones, M. d. M. (2017). Explaining the Adoption of Social Networks Sites for Sharing User-generated Content: A Revision of the UTAUT2. Computers in Human Behavior, 71(June), 209-217. https://doi.org/10.1016/j.chb.2017.02.007. 
Kang, J. Y. M. (2018). Showrooming, Webrooming, and User-generated Content Creation in the Omnichannel Era. Journal of Internet Commerce, 17(2), 145-169.

https://doi.org/10.1080/15332861.2018.1433907.

Kozup, J. C., Creyer, E. H., \& Burton, S. (2003). Making Healthful Food Choices: The Influence of Health Claims and Nutrition Information on Consumers' Evaluations of Packaged Food Products and Restaurant Menu Items. Journal of Marketing, 67(2), 19-34. https://doi.org/10.1509/jmkg.67.2.19.18608.

Lemon, K. N., \& Verhoef, P. C. (2016). Understanding Customer Experience Throughout the Customer Journey. Journal of Marketing, 80(6), 69-96. https://doi.org/10.1509/jm.15.0420.

Maharsi, D. A. P. (2012). Perilaku Penemuan Informasi untuk Berbelanja Online (Studi Kualitatif tentang Perilaku Penemuan Informasi Produk dan Gaya Hidup Berbelanja Online di Kalangan Wanita Pekerja di Sektor Swasta di Kota Surabaya). Ilmu Informasi dan Perpustakaan Fisip Unair, 1-18.

Mangkuto, W. S. (2019). Raup Triliunan Rupiah, Industri Kecantikan Sasar Kaum Pria. CNBC Indonesia, Lifestyle, 20 Mei. Diakses tanggal 15 Januari $2021 \mathrm{di}$ https://www.cnbcindonesia.com/lifestyle/20190520114508-33-73539/raup-triliunanrupiah-industri-kecantikan-sasar-kaum-pria/2.

Mothersbaugh, D. L., \& Hawkins, D. I. (2015). Consumer Behavior: Building Marketing Strategy. 13th Edition. New York: McGraw-Hill Education.

Nielsen.com (2019). E-commerce: The Next Frontier, Thrive in the World of New Retail. Nielsen. Diakses tanggal 15 Januari 2021 di https://www.nielsen.com/wpcontent/uploads/sites/3/2019/04/ ECom_the_next_frontier.pdf

Nurhayati, N. (2014). Pengembangan Program Bimbingan Karir Berbasis Teori Karir Holland. Thesis. Pendidikan Psikologi dan Bimbingan, Universitas Pendidikan Indonesia.

Oum, S., \& Han, D. (2011). An Empirical Study of the Determinants of the Intention to Participate in User-created Contents (UCC) Services. Expert Systems with Applications, 38(12), 15110-15121. https://doi.org/10.1016/j.eswa.2011.05.098.

Putri, A. S. (2020). Usia Berapa Perempuan Sudah Mulai Menggunakan Makeup dan Produk Skincare?. Fimela, Beauty, 23 Januari. Diakses tanggal 15 Januari 2021 di https://www.fimela.com/beauty/read/4161333/usia-berapa-perempuan-sudah-mulaimenggunakan-makeup-dan-produk-skincare.

Rodríguez-Torrico, P., Cabezudo, R. S. J., \& Martín, S. S. (2017). Tell me what they are like and I will tell you where they buy: An Analysis of Omnichannel Consumer Behavior. Computers in Human Behavior, 68, 465-471. https://doi.org/10.1016/j.chb.2016.11.064.

Schindler, D. W. (1998). Replication versus Realism: The Need for Ecosystem-scale Experiments. Ecosystems, 1(4), 323-334. https://doi.org/10.1007/s100219900026.

Smith, J. (2015). 3 Ways Brick-and-Mortar Stores can Win at Webrooming. Multichannel Merchant. Diakses tanggal 15 Januari 2021 di http://multichannelmerchant.com/ecommerce/3-ways-brick-and-mortar-storescanwin-atwebrooming-03082015. 
Sugiyono, S. (2010). Metode Penelitian Kuantitatif, Kualitatif, dan R\&D. Bandung: CV Alfabeta.

Syah, M. (2010). Psikologi Pendidikan dengan Pendekatan Baru. Bandung: PT. Remaja Rosdakarya.

van Bruggen, G. H., Antia, K. D., Jap, S. D., Reinartz, W. J., \& Pallas, F. (2010). Managing Marketing Channel Multiplicity. Journal of Service Research, 13(3), 331-340. https://doi.org/10.1177/1094670510375601.

Wilson, A., Murphy, H., \& Fierro, J. C. (2012). Hospitality and Travel: The Nature and Implications of User-Generated Content. Cornell Hospitality Quarterly, 53(3), 220228. https://doi.org/10.1177/1938965512449317.

Yadav, M. S., \& Pavlou, P. A. (2014). Marketing in Computer-mediated Environments: Research Synthesis and New Directions. Journal of Marketing, 78(1), 20-40. https://doi.org/10.1509/jm.12.0020. 